\title{
Prevalence and risk factors for refractive errors in the South Indian adult population:The Andhra Pradesh Eye disease study
}

\author{
Sannapaneni Krishnaiah ${ }^{1,2,3}$ \\ Marmamula Srinivas ${ }^{1,2,3}$ \\ Rohit C Khanna',2 \\ Gullapalli N Rao ${ }^{1,2,3}$ \\ 'L V Prasad Eye Institute, Banjara \\ Hills, Hyderabad, India; ${ }^{2}$ International \\ Center for Advancement of Rural \\ Eye Care, LV Prasad Eye Institute, \\ Banjara Hills, Hyderabad, India; ${ }^{3}$ Vision \\ CRC, University of New South Wales, \\ Sydney, NSW, Australia
}

\begin{abstract}
Aim: To report the prevalence, risk factors and associated population attributable risk percentage (PAR) for refractive errors in the South Indian adult population.

Methods: A population-based cross-sectional epidemiologic study was conducted in the Indian state of Andhra Pradesh. A multistage cluster, systematic, stratified random sampling method was used to obtain participants $(n=10293)$ for this study.

Results: The age-gender-area-adjusted prevalence rates in those $\geq 40$ years of age were determined for myopia (spherical equivalent [SE] $<-0.5$ D) $34.6 \%$ (95\% confidence interval [CI]: 33.1-36.1), high-myopia (SE < -5.0 D) 4.5\% (95\% CI: 3.8-5.2), hyperopia (SE > +0.5 D) 18.4\% (95\% CI: 17.1-19.7), astigmatism (cylinder < -0.5 D) 37.6\% (95\% CI: 36-39.2), and anisometropia (SE difference between right and left eyes $>0.5$ D) $13.0 \%$ (95\% CI: 11.9-14.1). The prevalence of myopia, astigmatism, high-myopia, and anisometropia significantly increased with increasing age (all $\mathrm{p}<0.0001$ ). There was no gender difference in prevalence rates in any type of refractive error, though women had a significantly higher rate of hyperopia than men $(\mathrm{p}<0.0001)$. Hyperopia was significantly higher among those with a higher educational level (odds ratio [OR] 2.49; 95\% CI: 1.51-3.95) and significantly higher among the hypertensive group (OR 1.24; 95\% CI: 1.03-1.49). The severity of lens nuclear opacity was positively associated with myopia and negatively associated with hyperopia.

Conclusions: The prevalence of myopia in this adult Indian population is much higher than in similarly aged white populations. These results confirm the previously reported association between myopia, hyperopia, and nuclear opacity.
\end{abstract}

Keywords: refractive errors, risk factors, population attributable risk percent, population-based cross-sectional study, southern India

\section{Introduction}

Refractive error is one of the most common causes of visual impairment around the world and is the second leading cause of treatable blindness. ${ }^{1}$ Refractive error is a remediable cause of visual impairment, with correction of significant refractive error being a priority of VISION 2020: The Right to Sight, the joint global initiative of the World Health Organization's (WHO) and the International Agency for the Prevention of Blindness. ${ }^{2}$ Refractive error has a severe social and economic impact on individuals and communities, restricting educational and employment opportunities of otherwise healthy individuals. Compared to cataract, early onset of refractive error accounts for twice as many blind-person years. ${ }^{1}$

Refractive errors were found to be responsible for a significant proportion of blindness and moderate visual impairment in the population of India. ${ }^{3,4}$ Several other factors including genetic ${ }^{5}$ and environmental influences like nearwork, ${ }^{6}$ night lighting, ${ }^{7}$ and UV exposure ${ }^{8}$ are also believed to play a role in determining the refractive status of the eye, but the true underlying mechanisms involved remain unclear. 
Refractive error has previously been shown to change as people age. ${ }^{9,10}$ Both longitudinal and cross-sectional studies have found an increase in hyperopia with increasing age after the early 30 s. ${ }^{11}$ As refractive errors are a major cause of mild to moderate visual impairment in the population, knowledge of the prevalence and risk factors of refractive errors would help plan effective refraction services.

Population attributable risk percent (PAR) corresponds to the percentage of risk in the community that is associated with exposure to a risk factor and is used to prioritize public health interventions. ${ }^{12,13}$ To the best of our knowledge, the PAR for refractive errors has not been reported for the Indian population. The purpose of this study was to estimate the prevalence of different refractive errors and investigate the possible associated risk factors for refractive errors and to estimate the PAR associated with these risk factors for refractive errors. In this study the authors attempted to report the data on adult population (more than or equal to 40 years of age) so as to compare the results with other published reports.

\section{Materials and methods}

The details of the design of Andhra Pradesh Eye Disease Study (APEDS), conducted during 1996-2000, following the tenets of the Helsinki Declaration, have been described previously. ${ }^{4,14,15}$ Approval of the Ethics Committee of the Institute was obtained for the study design.

Briefly, a multistage sampling procedure was used to select the study sample of 10,000 persons, 5000 each below and above 30 years of age based on the assumption that a $0.5 \%$ prevalence of an eye disease in either of these groups may be of public health significance. This sample would estimate the prevalence from $0.3 \%$ to $0.8 \%$ at the $95 \%$ CI level. One urban and three rural areas from different parts of the southern Indian state of Andhra Pradesh were selected, with the aim of including approximately 2500 participants in each area, such that these would roughly reflect the urban-rural and socioeconomic distribution of the population of this state. These four areas were located in Hyderabad (urban), West Godavari district (prosperous rural), and Adilabad and Mahabubnagar districts (poor rural). The details of the sampling strategy have been described in detail elsewhere. ${ }^{14,15}$

\section{Interview}

The participants were interviewed in detail by trained field investigators after obtaining their informed consent. ${ }^{15}$ The interview was performed in a masked manner. A structured questionnaire was used to collect information on risk factors of systemic diseases and personal habits such as smoking.
Hypertension was deemed to be present if a subject had a history of high blood pressure diagnosed by a physician and/ or was currently using antihypertensive medications and/or had a blood pressure reading of $\geq 140 / 90 \mathrm{~mm} \mathrm{Hg}$. Diabetes was deemed to be present if a subject had a history of diabetes and/or was on antidiabetic medication and/or were found to have diabetic retinopathy on clinical examination. Subjects not providing the history of diabetes but with retinopathy presumably from diabetes were subjected to a random blood sugar test. If the random blood sugar was above $120 \mathrm{mg} / \mathrm{dl}$, the subject underwent a fasting blood sugar estimation on a subsequent day after an overnight fast. History of duration of diabetes since diagnosis was also documented.

\section{Clinical examination}

Subjects were brought to a makeshift clinic set up for this study. Informed consent was obtained before the examination. The clinical examination included measurement of distance and near visual acuity with $\log$ MAR charts, refraction, and a detailed examination of anterior segment, gonioscopy, dilatation, a detailed examination of lens, vitreous and posterior segment, and visual fields based on uniform predefined criteria. ${ }^{3,4,15}$

Refraction was attempted on all subjects $\geq 40$ years of age who presented with distance and/or near visual acuity worse than 20/20 in either eye. Objective refraction was performed by an optometrist using a streak retinoscope, which was further refined by subjective refraction. For subjects with distance and near visual acuity of 20/20 or better with current refractive correction, this correction was taken as the refractive error. Subjects who were not using optical correction and had distance and near visual acuity of 20/20 or better were considered as not having refractive error. ${ }^{16}$

\section{Dilated examination}

The nuclear opacity was graded according to the Lens Opacities Classification System III (LOCS III); ${ }^{17}$ cortical and posterior subcapsular cataracts were graded using the Wilmer Classification. ${ }^{18}$ Inter-rater reliability was done between the principal investigator and the clinicians who were specially trained in grading the cataract at the slit-lamp applying LOCS III and Wilmer classifications. ${ }^{15}$ The inter-rater reliability was also determined between the principal investigator and the clinicians at the APEDS clinic for assessment of agerelated maculopathy (ARM), the early stage of age-related macular degeneration (AMD), AMD, and diabetic retinopathy (DR). The details of training and other procedures have been reported elsewhere. ${ }^{15}$ Those who graded lens status, 
ARM, and AMD were masked to the interview data and the investigators who administered the questionnaire in the field were masked to the clinical findings. Subjects who were physically unable to attend the clinic were examined at home with portable equipment.

Stereo examination of the disc and macula was performed with a $78 \mathrm{D}$ lens on a slit-lamp; a $20 \mathrm{D}$ lens was used for indirect ophthalmoscopy. Anterior segment pathology was photographed with a Nikon camera (Nikon Corporation, Tokyo, Japan) mounted on the slit-lamp, and posterior segment pathology with a Zeiss (Carl Ziess, Jena, Germany) fundus camera. All photographs were classified according to an international classification and grading system of AMD. ${ }^{19}$ The cases of ARM and AMD thus detected were also confirmed by the principal investigator. While AMD was classified as "wet" (neovascular) or "dry" (atrophic), they were combined for analysis in the present report.

\section{Definitions}

For our definitions of myopia, high myopia, hyperopia, and anisometropia, the refractive data were converted to spherical equivalent (SE), which is derived by adding the spherical component of the refraction to half the cylindrical component. Because the correlation between the right and left eyes for SE was high $(\mathrm{r}=0.70, \mathrm{P}=0.01)$, for the analysis of all refractive errors other than anisometropia, we present data only on the right eye. Myopia was defined as present if $\mathrm{SE}<-0.5 \mathrm{D}$, high-myopia if $\mathrm{SE}<-5.0 \mathrm{D}$, hyperopia if $\mathrm{SE}>+0.5 \mathrm{D}$, astigmatism if cylinder $<-0.5 \mathrm{D}$, and anisometropia if SE difference between right and left eyes $>0.5 \mathrm{D}$.

\section{Smoking status}

For this analysis, subjects were categorized as "never" smokers (never smoked), current smokers, and prior smokers (those who previously smoked but reported not smoking currently). Current and prior smokers were those who had smoked for a minimum of one year. Subjects who had never smoked, or had smoked for less than one year were considered to be "never" smokers.

We defined ARM and AMD based on the published International Classification and grading system. ${ }^{19}$ Of the 10,293 subjects examined, data were analyzed for the 3,723 (36.2\%) subjects who were $\geq 40$ years old.

\section{Statistical analysis}

The prevalence of different refractive errors and other estimates in our sample were adjusted for the estimated age and gender distribution of the population in India for the year 2000 (http://www.census.gov). The 95\% CIs were calculated by assuming a Poisson distribution ${ }^{20}$ for prevalence $<1 \%$, and normal approximation of binomial distribution for prevalence of $1 \%$ or more. Variables of interest were first tested for associations with refractive errors in bivariable analysis using the Fisher's exact test or Chi-square test as appropriate. Variables associated with refractive errors in bivariable analysis were further tested in a backwards, stepwise multivariable logistic regression model adjusting for potential confounders. Population attributable risk percentages for the individual factors identified in the multivariable logistic regression model were calculated for this study using Levin's formula. ${ }^{21}$ The SPSS software (version 12.0 for Windows; SPSS Inc., Chicago, IL, USA) was used for statistical analysis. A two-tailed $P$-value of less than 0.05 was considered statistically significant.

\section{Results}

\section{Study population}

A total of 2522 (85.4\%) of 2954 eligible participants from urban Hyderabad and 7771 (88\%) of 8832 eligible participants from three rural areas of Andhra Pradesh participated in the study. The study population was representative of the urban and rural population of the state as a whole. In this study the data were analyzed for those more than or equal to 40 years of age $(n=3723)$. Data on refractive errors were analysed for 3642 (97.8\%) subjects (excluding 81 subjects with aphakia/pseudophakia/total cataract in both eyes). For urban residents the age ranged from 40 to 92 years $(52.9 \pm 10.7$; median 50 years $) ; 410(45.6 \%)$ were men. The age for rural residents ranged from 40 to 95 years $(54.5 \pm 10.3$; median 54 years) and 1301 (47.4\%) were men.

A total of $1328(36.5 \%)$ subjects were classified as myopic, 661 (18.1\%) subjects were classified as hyperopic, 1393 (38.2\%) subjects were classified as having astigmatism, and $496(13.6 \%)$ subjects were classified as having anisometropia. One hundred and seventy five (4.8\%) subjects had high myopia. The crude age-gender-area-adjusted prevalence of different refractive errors is shown in Table 1. The age-gender-area-adjusted prevalence of myopia was $34.6 \%$ (95\% CI: 33.1-36.1) with higher prevalence rates in men $(37.9 \%, 95 \%$ CI: 35.6-40.2) than in women $(35.2 \%$, 95\% CI: 33.1-37.4). There was no statistically significant difference between the two sexes in the prevalence estimates of all refractive errors, except for hyperopia, in which the prevalence was significantly higher among women $(13.3 \%$ vs $22.4 \%$; $<<0.0001$ ) (Table 2 ). 
Table I Crude and adjusted prevalence estimates of refractive errors in an adult population of Southern India $(n=3642)$

\begin{tabular}{lll}
\hline & \multicolumn{2}{l}{ Prevalence etimates (\%) } \\
\cline { 2 - 3 } & Crude & Adjusted* $(95 \% \mathrm{Cl})$ \\
\hline Myopia & 36.5 & $34.6(33.1-36 . \mathrm{I})$ \\
High mopia & 4.8 & $4.5(3.8-5.2)$ \\
Hyperopia & 18.1 & $18.4(17.1-19.7)$ \\
Astigmatism & 38.2 & $37.6(36-39.2)$ \\
Anisometropia & 13.6 & $13.0(11.9-14.1)$ \\
\hline
\end{tabular}

Note: "Age, gender and area adjusted according to the 2000 Indian population. Abbreviation: $\mathrm{Cl}$, confidence interval.

Table 2 shows the prevalence estimates of myopia, high myopia, and hyperopia by different characteristics. The prevalence of myopia increased significantly $(p<0.0001)$ with age and severity of nuclear lens opacity $(\mathrm{p}<0.0001)$. The prevalence of myopia decreased significantly $(\mathrm{p}<0.0001)$ with increased socioeconomic status and with increased educational level ( $\mathrm{p}<0.0001)$. The prevalence of myopia was also significantly higher among rural residents compared to urban residents (38\% vs $31.9 \%$; $\mathrm{p}=0.001)$ and in current smokers as compared to never smokers (43\% vs $33.5 \%$; $\mathrm{p}<0.0001)$. The prevalence of myopia was significantly higher in subjects with ARM compared with subjects without ARM (48.5\% vs 35.3\%; p $<0.0001)$. There were no significant associations of myopia with other factors: gender, hypertension, and diabetes. A similar association was seen in the case of high myopia (Table 2). The prevalence of hyperopia was significantly higher $(\mathrm{p}=0.001)$ in the group aged 50 to 59 years (Table 2). Women had significantly higher prevalence of hyperopia $(22.4 \%$ vs $13.3 \%$; $p<0.0001)$ compared to men. The prevalence of hyperopia was also significantly higher in urban residents when compared to rural residents $(24.9 \%$ vs $15.9 \% ; \mathrm{p}<0.0001)$ and also higher in subjects with diabetes when compared to the subjects without diabetes $(24.3 \%$ vs $17.8 \%$; $<0.0001)$. Table 3 shows the prevalence estimates of astigmatism and anisometropia by different characteristics. The results of the multivariable logistic regression analysis for myopia, hyperopia, astigmatism, and anisometropia are presented in Tables 4 and 5.

\section{Discussion}

To our knowledge, this study is the first to provide the population attributable risk percentage (PAR\%) data on different types of refractive errors in adult Asians. Data from this population-based study demonstrated the expected association between age and different types of refractive errors. Extremely low socioeconomic status, illiteracy, rural residence, smoking, ARM, and severity of nuclear opacity were significantly associated with myopia. Based on our results, smoking, hypertension, diabetes mellitus, and early AMD were identified as modifiable risk factors, whereas age, nuclear cataract and AMD were identified as nonmodifiable risk factors.

Table 2 Prevalence estimates of myopia, high myopia, and hyperopia by potential risk factors in the study population $(\mathrm{n}=3642)$

\begin{tabular}{|c|c|c|c|c|c|c|c|}
\hline & \multirow[b]{2}{*}{ Total population } & \multicolumn{2}{|c|}{$\begin{array}{l}\text { Myopia } \\
(\mathrm{SE}<-0.5 \mathrm{D})\end{array}$} & \multicolumn{2}{|c|}{$\begin{array}{l}\text { High myopia } \\
\text { (SE }<-5.0 \text { D) }\end{array}$} & \multicolumn{2}{|c|}{$\begin{array}{l}\text { Hyperopia } \\
(\mathrm{SE}>+0.5 \mathrm{D})\end{array}$} \\
\hline & & $\bar{n}$ & $\%(95 \% \mathrm{Cl})$ & $\bar{n}$ & $\%(95 \% \mathrm{Cl})$ & $\bar{n}$ & $\%(95 \% \mathrm{Cl})$ \\
\hline \multicolumn{8}{|l|}{ Age (y) } \\
\hline $40-49$ & 1416 & 272 & $19.2(17.2-21.3)$ & 31 & $2.2(1.4-2.9)$ & 251 & 17.7 (I5.7-19.7) \\
\hline $50-59$ & 1035 & 396 & $38.3(35.3-41.2)$ & 50 & $4.8(3.5-6.1)$ & 226 & $21.8(19.3-24.4)$ \\
\hline $60-69$ & 858 & 480 & $56(52.7-59.3)$ & 71 & $8.3(6.4-10.1)$ & 126 & $14.7(12.3-17.1)$ \\
\hline \multirow[t]{2}{*}{$70+$} & 333 & 180 & $54.1(48.7-59.4)$ & 23 & $6.9(4.2-9.6)$ & 58 & $17.4(|3.3-2| .5)$ \\
\hline & & & $\mathrm{P}<0.000 \mathrm{I}$ & & $P<0.000 I$ & & $P=0.001$ \\
\hline \multicolumn{8}{|l|}{ Gender } \\
\hline Male & 1711 & 648 & $37.9(35.6-40.2)$ & 89 & $5.2(4.1-6.1)$ & 228 & | $3.3(|| .7-\mid 4.9)$ \\
\hline \multirow[t]{2}{*}{ Female } & 1931 & 680 & $35.2(33.1-37.4)$ & 86 & $4.5(3.5-5.4)$ & 433 & $22.4(20.6-24.3)$ \\
\hline & & & $P=0.105$ & & $P=0.313$ & & $\mathrm{P}<0.000 \mathrm{I}$ \\
\hline \multicolumn{8}{|c|}{ Socioeconomic } \\
\hline \multicolumn{8}{|l|}{ status $^{\dagger}$} \\
\hline$\leq 200$ & 408 & 173 & $42.4(37.6-47.2)$ & 27 & $6.6(4.2-9.0)$ & 58 & $14.2(10.8-17.6)$ \\
\hline $20 \mathrm{I}-500$ & 1756 & 686 & $39.1(36.8-41.4)$ & 101 & $5.8(4.7-6.8)$ & 264 & $15.0(13.4-16.7)$ \\
\hline $50 I-2000$ & 1283 & 403 & $31.4(28.9-33.9)$ & 42 & $3.3(2.3-4.2)$ & 284 & $22.1(19.9-24.4)$ \\
\hline
\end{tabular}


Table 2 (Continued)

\begin{tabular}{|c|c|c|c|c|c|c|c|}
\hline & \multirow[b]{2}{*}{ Total population } & \multicolumn{2}{|c|}{$\begin{array}{l}\text { Myopia } \\
(\mathrm{SE}<-0.5 \mathrm{D})\end{array}$} & \multicolumn{2}{|c|}{$\begin{array}{l}\text { High myopia } \\
(\mathrm{SE}<-5.0 \mathrm{D})\end{array}$} & \multicolumn{2}{|c|}{$\begin{array}{l}\text { Hyperopia } \\
\text { (SE }>+0.5 \text { D) }\end{array}$} \\
\hline & & $\mathbf{n}$ & $\%(95 \% \mathrm{Cl})$ & $\mathbf{n}$ & $\%(95 \% \mathrm{Cl})$ & $\mathbf{n}$ & $\%(95 \% \mathrm{Cl})$ \\
\hline \multirow[t]{2}{*}{$>2000$} & 143 & 38 & $26.6(19.3-33.8)$ & 2 & $1.4(0.0-3.3)$ & 49 & $34.3(26.5-42.0)$ \\
\hline & & & $\mathrm{P}<0.000 \mathrm{I}$ & & $P=0.00 I$ & & $P<0.000 I$ \\
\hline \multicolumn{8}{|l|}{ Educational level ${ }^{\ddagger}$} \\
\hline Illiterate & 2156 & 916 & $42.5(40.4-44.6)$ & 126 & $5.8(4.9-6.8)$ & 291 & $13.5(12.1-14.9)$ \\
\hline Class I-5 & 752 & 234 & 3І.I (27.8-34.4) & 26 & $3.5(2.2-4.8)$ & 189 & $25.1(22.0-28.2)$ \\
\hline Class 6-10 & 469 & 107 & $22.8(19.0-26.6)$ & 14 & $3.0(1.4-4.5)$ & 110 & $23.5(19.6-27.3)$ \\
\hline Class $11-12$ & III & 36 & $32.4(23.7-4 \mid .1)$ & 5 & $4.5(1.0-8.4)$ & 26 & $23.4(|5.5-3| .3)$ \\
\hline \multirow[t]{2}{*}{ Higher than class 12} & 148 & 32 & $21.6(14.9-28.3)$ & 4 & $2.7(0.1-5.3)$ & 44 & $29.7(22.4-37.1)$ \\
\hline & & & $\mathrm{P}<0.000 \mathrm{I}$ & & $P=0.012$ & & $\mathrm{P}<0.000 \mathrm{I}$ \\
\hline \multicolumn{8}{|l|}{ Area } \\
\hline Urban & 899 & 287 & $31.9(28.9-34.9)$ & 34 & $3.8(2.5-5.0)$ & 224 & $24.9(22.1-27.7)$ \\
\hline \multirow[t]{2}{*}{ Rural } & 2743 & 1041 & $38.0(36.1-39.8)$ & $|4|$ & $5.1(4.2-5.9)$ & 437 & $15.9(14.6-17.3)$ \\
\hline & & & $P=0.001$ & & $P=0.109$ & & $P<0.000 I$ \\
\hline \multicolumn{8}{|l|}{ Hypertension } \\
\hline No & $|88|$ & 682 & $36.3(34.1-38.4)$ & 92 & $4.9(3.9-5.9)$ & 287 & $15.3(13.6-16.9)$ \\
\hline \multirow[t]{2}{*}{ Yes } & $|76|$ & 646 & $36.7(34.5-38.9)$ & 83 & $4.7(3.7-5.7)$ & 374 & $21.2(19.3-23.1)$ \\
\hline & & & $P=0.783$ & & $P=0.817$ & & $P<0.000 I$ \\
\hline \multicolumn{8}{|l|}{ Diabetes } \\
\hline No & 3456 & 1266 & $36.7(35.1-38.3)$ & 168 & $4.9(4.1-5.6)$ & 616 & $17.8(16.5-19.1)$ \\
\hline \multirow[t]{2}{*}{ Yes } & 185 & 60 & $32.4(25.7-39.2)$ & 7 & $3.8(1.0-6.5)$ & 45 & $24.3(18.1-30.5)$ \\
\hline & & & $P=0.272$ & & $P=0.601$ & & $P=0.031$ \\
\hline \multicolumn{8}{|l|}{ Smoking } \\
\hline Never a smoker & 2293 & 767 & $33.5(31.5-35.4)$ & 90 & $3.9(3.1-4.7)$ & 508 & $22.2(20.5-23.9)$ \\
\hline Current smoker & 1057 & 454 & $43.0(40.0-45.9)$ & 65 & $6.1(4.7-7.6)$ & 102 & 9.6 (7.9-1 I.4) \\
\hline \multirow[t]{2}{*}{ Ex-smoker } & 291 & 107 & $36.8(31.2-42.3)$ & 20 & $6.9(4.0-9.8)$ & 51 & $\mid 7.5(|3.2-2| .9)$ \\
\hline & & & $P<0.0001$ & & $P=0.005$ & & $P<0.000 I$ \\
\hline \multicolumn{8}{|l|}{ AMD $\S$} \\
\hline No & 3577 & 1297 & $36.3(34.7-37.8)$ & 169 & $4.7(4.0-5.3)$ & 646 & $18.1(16.8-19.3)$ \\
\hline \multirow[t]{2}{*}{ Yes } & 64 & 31 & $48.4(36.2-60.7)$ & 6 & $9.4(2.2-16.5)$ & 15 & $23.4(13.1-33.8)$ \\
\hline & & & $P=0.050$ & & $P=0.126$ & & $P=0.255$ \\
\hline \multicolumn{8}{|l|}{ ARM } \\
\hline No & 3315 & 1170 & $35.3(33.7-36.9)$ & 154 & $4.6(3.9-5.3)$ & 602 & $18.2(16.8-19.5)$ \\
\hline \multirow[t]{2}{*}{ Yes } & 326 & 158 & $48.5(43.0-53.9)$ & 21 & $6.4(3.8-9.1)$ & 59 & I8.| (13.9-22.3) \\
\hline & & & $P<0.000 I$ & & $P=0.173$ & & $P=1.000$ \\
\hline \multicolumn{8}{|l|}{$\begin{array}{l}\text { Nuclear cataract } \\
\text { (LOCS III grade) }\end{array}$} \\
\hline Grade $<2$ & 1700 & 229 & |3.5 (| | $.9-\mid 5.1)$ & 16 & $1.0(0.5-1.4)$ & 354 & $20.8(18.9-22.8)$ \\
\hline Grade 2 to 3.5 & 1717 & 998 & $58.1(55.8-60.4)$ & 133 & $7.7(6.5-9.0)$ & $27 I$ & $15.8(14 .|-| 7.5)$ \\
\hline \multirow[t]{2}{*}{ Grade $>3.5$} & 158 & 94 & $59.5(51.8-67.1)$ & 26 & $16.5(10.7-22.2)$ & 13 & $8.2(3.9-12.5)$ \\
\hline & & & $P<0.0001$ & & $P<0.000 I$ & & $P<0.000 I$ \\
\hline
\end{tabular}

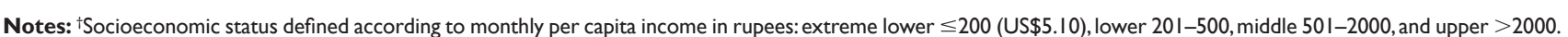
Data on socioeconomic status not available for 52 subjects; ${ }^{\ddagger}$ Data on educational level not available for six subjects; ${ }^{\circledR} \mathrm{AMD}$, age-related macular degeneration (includes both dry and wet forms). 
Table 3 Prevalence estimates of astigmatism and anisometropia by potential risk factors in the study population $(n=3642)$

\begin{tabular}{|c|c|c|c|c|c|}
\hline & \multirow[b]{2}{*}{ Total population } & \multicolumn{2}{|c|}{$\begin{array}{l}\text { Astigmatism } \\
\text { (Cylinder }<-0.5 \mathrm{D})\end{array}$} & \multicolumn{2}{|c|}{$\begin{array}{l}\text { Anisometropia } \\
\text { (SE Difference }>0.5 \mathrm{D})\end{array}$} \\
\hline & & $\mathbf{N}$ & $\%(95 \% \mathrm{Cl})$ & $\mathbf{N}$ & $\%(95 \% \mathrm{Cl})$ \\
\hline \multicolumn{6}{|l|}{ Age (y) } \\
\hline $40-49$ & 1416 & 424 & $29.9(27.6-32.3)$ & 99 & $7.0(5.7-8.3)$ \\
\hline $50-59$ & 1035 & 468 & $45.2(42.2-48.2)$ & 156 & I5.I (I2.9-17.3) \\
\hline $60-69$ & 858 & 364 & $42.5(39.2-45.8)$ & 166 & $19.3(|6.7-2| .9)$ \\
\hline \multirow[t]{2}{*}{$70+$} & 333 & 137 & $4 I . I(35.9-46.4)$ & 75 & $22.5(18.0-27.0)$ \\
\hline & & & $P<0.0001$ & & $P<0.0001$ \\
\hline \multicolumn{6}{|l|}{ Gender } \\
\hline Male & 1711 & 667 & $39.0(36.7-41.3)$ & 222 & $13.0(\mid 1.4-14.6)$ \\
\hline \multirow[t]{2}{*}{ Female } & 1931 & 726 & $37.6(35.5-39.8)$ & 274 & $14.2(12.6-15.7)$ \\
\hline & & & $P=0.412$ & & $P=0.288$ \\
\hline \multicolumn{6}{|l|}{ Socioeconomic status ${ }^{\dagger}$} \\
\hline$\leq 200$ & 408 & 160 & $39.2(34.5-44.0)$ & 55 & $13.5(10.2-16.8)$ \\
\hline $20 \mathrm{I}-500$ & 1756 & 660 & $37.6(35.3-39.9)$ & 249 & $14.2(12.5-15.8)$ \\
\hline $50 I-2000$ & 1283 & 508 & $39.6(36.9-42.3)$ & 172 & $13.4(|| .5-15.3)$ \\
\hline \multirow[t]{2}{*}{$>2000$} & 143 & 49 & $34.3(26.5-42.0)$ & 11 & $7.7(3.3-12.1)$ \\
\hline & & & $P=0.480$ & & $P=0.187$ \\
\hline \multicolumn{6}{|l|}{ Educational level ${ }^{\ddagger}$} \\
\hline Illiterate & 2156 & 837 & $38.8(36.8-40.9)$ & 331 & $15.4(13.8-16.9)$ \\
\hline Class I-5 & 752 & 289 & $38.4(35.0-41.9)$ & 107 & $14.2(11.7-16.7)$ \\
\hline Class $6-10$ & 469 & 167 & $35.6(31.3-39.9)$ & 37 & $7.9(5.4-10.3)$ \\
\hline Class $11-12$ & 111 & 43 & $38.7(29.7-47.8)$ & 10 & $9.0(3.7-14.3)$ \\
\hline \multirow[t]{2}{*}{ Higher than class 12} & 148 & 55 & $37.2(29.4-44.9)$ & 10 & $6.8(2.7-10.8)$ \\
\hline & & & $P=0.773$ & & $P<0.000 I$ \\
\hline \multicolumn{6}{|l|}{ Area } \\
\hline Urban & 899 & 309 & $34.4(31.3-37.5)$ & 85 & $9.5(7.5-11.4)$ \\
\hline \multirow[t]{2}{*}{ Rural } & 2743 & 1084 & $39.5(37.7-41.4)$ & 411 & $15.0(13.6-16.3)$ \\
\hline & & & $P=0.006$ & & $P<0.000 I$ \\
\hline \multicolumn{6}{|l|}{ Hypertension } \\
\hline No & $188 \mid$ & 686 & $36.5(34.3-38.6)$ & 247 & I3.I (II.6-14.7) \\
\hline \multirow[t]{2}{*}{ Yes } & $176 \mid$ & 707 & $40.2(37.9-42.5)$ & 249 & $14.1(12.5-15.8)$ \\
\hline & & & $P=0.122$ & & $P=0.384$ \\
\hline \multicolumn{6}{|l|}{ Diabetes } \\
\hline No & 3456 & 1314 & $38.0(36.4-39.6)$ & 473 & $13.7(|2.5-| 4.8)$ \\
\hline \multirow[t]{2}{*}{ Yes } & 185 & 79 & $42.7(35.6-49.8)$ & 23 & $12.4(7.7-17.2)$ \\
\hline & & & $P=0.214$ & & $P=0.74 I$ \\
\hline \multicolumn{6}{|l|}{ Smoking } \\
\hline Never a smoker & 2293 & 846 & $36.9(34.9-38.9)$ & 302 & $13.2(|| .8-14.6)$ \\
\hline Current smoker & 1057 & 417 & $39.5(36.5-42.4)$ & 146 & $13.8(\mid 1.7-15.9)$ \\
\hline \multirow[t]{2}{*}{ Ex-smoker } & 291 & 130 & $44.7(39.0-50.4)$ & 48 & $16.5(12.2-20.8)$ \\
\hline & & & $P=0.024$ & & $P=0.291$ \\
\hline \multicolumn{6}{|l|}{$\mathrm{AMD}^{\S}$} \\
\hline No & 3577 & 1355 & $37.9(36.3-39.5)$ & 479 & $13.4(\mid 2.3-14.5)$ \\
\hline \multirow[t]{2}{*}{ Yes } & 64 & 38 & $59.4(47.3-71.4)$ & 17 & $26.6(15.7-37.4)$ \\
\hline & & & $P=0.001$ & & $P=0.005$ \\
\hline
\end{tabular}


Table 3 (Continued)

\begin{tabular}{|c|c|c|c|c|c|}
\hline & \multirow[b]{2}{*}{ Total population } & \multicolumn{2}{|c|}{$\begin{array}{l}\text { Astigmatism } \\
\text { (Cylinder }<-0.5 \mathrm{D})\end{array}$} & \multicolumn{2}{|c|}{$\begin{array}{l}\text { Anisometropia } \\
\text { (SE Difference >0.5 D) }\end{array}$} \\
\hline & & $\mathbf{N}$ & $\%(95 \% \mathrm{Cl})$ & $\mathbf{N}$ & $\%(95 \% \mathrm{Cl})$ \\
\hline \multicolumn{6}{|l|}{ ARM } \\
\hline No & 3315 & 1257 & $37.9(36.3-39.6)$ & 436 & $13.2(\mid 2.0-14.3)$ \\
\hline \multirow[t]{2}{*}{ Yes } & 326 & 136 & $41.7(36.4-47.1)$ & 60 & $18.4(14.2-22.6)$ \\
\hline & & & $P=0.189$ & & $P=0.011$ \\
\hline \multicolumn{6}{|l|}{$\begin{array}{l}\text { Nuclear cataract } \\
\text { (LOCS III grade) }\end{array}$} \\
\hline Grade $<2$ & 1700 & 559 & $32.9(30.7-35.1)$ & - & - \\
\hline Grade 2 to 3.5 & 1717 & 767 & $44.7(42.3-46.9)$ & - & - \\
\hline \multirow[t]{2}{*}{ Grade $>3.5$} & 158 & 34 & $21.5(15.1-27.9)$ & - & - \\
\hline & & & $P<0.000 I$ & & \\
\hline
\end{tabular}

Notes: †Socioeconomic status defined according to monthly per capita income in rupees: extreme lower $\leq 200$ (US\$5. 10), lower 20I-500, middle 50I-2000, and upper $>2000$. Data on socioeconomic status not available for 53 subjects; ${ }^{\ddagger}$ Data on educational level not available for six subjects; ${ }^{\circledR} \mathrm{AMD}$, age-related macular degeneration (includes both dry and wet forms).

\section{Prevalence of different refractive errors}

An age-gender-area-adjusted prevalence of myopia was $34.6 \%$ (95\% CI: $33.1-36.1$ ) in Indian adults, which is slightly less than the prevalence of myopia $38.7 \%(95 \%$ CI: 35.5-42.1) of adult Chinese in Singapore. ${ }^{22}$ However, our prevalence estimate of myopia was almost twice the prevalence seen in similarly aged populations in Caucasians $(17.5 \%)^{23-26}$ and blacks $(21.9 \%){ }^{23,27}$ This confirms a widely held view that myopia is more common in East Asia, based on data in previous studies in selected populations. ${ }^{28-34} \mathrm{In}$ contrast, the prevalence of myopia in our Indian population is much higher than that in similarly aged elderly Caucasian populations: $14.7 \%$ in the Beaver Dam Eye Study, ${ }^{24}$ $11.1 \%$ in the Blue Mountains Eye Study, ${ }^{26}$ and $17.9 \%$ in the white group in the Baltimore Eye Survey. ${ }^{23}$ We found the prevalence of hyperopia (age-gender-area-adjusted prevalence: $18.4 \%$ ) was higher in this population, which is much less than among the elderly Chinese population in Taiwan $(59.0 \%){ }^{35}$

\section{Potential risk factors associated with refractive errors}

As reported in other populations worldwide, age was highly correlated with the prevalence of different refractive errors in our study. ${ }^{23,26,27,35-38}$ When age was entered in the multivariable logistic regression model as a covariate, adjusting for other potential confounders, for each unit (a year) of increment of age, the odds of increment of myopia were 1.06 (95\% CI: $1.05-1.07 ; p<0.0001)$ in this population. Because the age pattern of myopia was described half a century ago, ${ }^{39}$ the exact rationale for this observation is still controversial. One theory involves changes in the refractive index gradient of the lens with age. ${ }^{40}$

The association of gender and refractive error has not been well established. Our study shows a significantly higher prevalence of hyperopia in women as compared to men (adjusted OR 2.2 [95\% CI: 1.69-2.85]) a finding similar to other studies. $22,26,27,35$ This may be because women's eyes have a shorter axial length and shallower anterior chamber depth than those of men and hence a higher probability of being hyperopic. ${ }^{41}$

Our data showed a significant increase in myopia with nuclear cataract. Because nuclear cataract results from age-related changes in the lens, a significant interaction between age and nuclear cataract is responsible for this finding. Myopic shift in the very elderly group was found to be associated with age-related changes in the lens in a previous study in Melbourne. ${ }^{25}$ In the elderly, lens nuclear opacity becomes an additional significant predictor of refractive error. ${ }^{22,25,27,42,43}$ This is consistent with our findings that the degree of nuclear opacity was positively associated with the prevalence of myopia and inversely associated with the prevalence of hyperopia. Changes in the refractive index of the lens substantially influence the shift of refraction. Thus, denser nuclear cataract in the elderly may drive the refractive error in the minus direction, which makes the hyperopic shift less evident. This is supported by data from the longitudinal Beaver Dam Eye Study, ${ }^{44}$ which showed that after a 10 -year period, younger adults became more hyperopic, and whereas older adults and elderly people became 
Table 4 Multivariable logistic regression models assessing the adjusted odds ratio $(95 \% \mathrm{Cl})$ of refractive errors

\begin{tabular}{|c|c|c|c|c|}
\hline & $\begin{array}{l}\text { Myopia } \\
(\mathrm{SE}<-0.5 \mathrm{D})\end{array}$ & $\mathbf{P A R}^{\eta}$ & $\begin{array}{l}\text { Hyperopia } \\
\text { (SE > +0.5 D) }\end{array}$ & $\mathbf{P A R}^{\eta}$ \\
\hline \multicolumn{5}{|l|}{ Age (y) } \\
\hline $40-49$ & 1.00 & & 1.00 & \\
\hline $50-59$ & $1.22(0.98-1.52)$ & - & $1.72(1.37-2.16)$ & - \\
\hline $60-69$ & $1.62(1.28-2.06)$ & - & $1.24(1.00-1.66)$ & - \\
\hline$\geq 70$ & $1.45(1.05-1.98)$ & - & $1.68(I . \mid 3-2.5 \mathrm{I})$ & - \\
\hline \multicolumn{5}{|l|}{ Sex } \\
\hline Male & 1.00 & & 1.00 & \\
\hline Female & $0.81(0.65-1.02)$ & - & $2.2(1.69-2.85)$ & - \\
\hline \multicolumn{5}{|l|}{ Socioeconomic status } \\
\hline Extreme lower + lower & $1.23(1.03-1.46)$ & - & $0.8(0.66-0.96)$ & - \\
\hline Middle + upper & 1.00 & & 1.00 & \\
\hline \multicolumn{5}{|l|}{ Educational level } \\
\hline Illiterate & 1.00 & & 1.00 & \\
\hline Class I-5 & $0.60(0.48-0.74)$ & - & $2.47(1.96-3.11)$ & - \\
\hline Class 6-10 & $0.62(0.46-0.82)$ & - & $2.06(1.54-2.77)$ & - \\
\hline Class $11-12$ & $0.98(0.59-1.59)$ & - & $2.02(1.21-3.39)$ & - \\
\hline Higher than class 12 & $0.72(0.44-1.19)$ & - & $2.49(1.51-3.95)$ & - \\
\hline \multicolumn{5}{|l|}{ Area } \\
\hline Urban & 1.00 & & 1.00 & \\
\hline Rural & $1.44(1.16-1.78)$ & - & $0.71(0.57-0.89)$ & - \\
\hline \multicolumn{5}{|l|}{ Hypertension } \\
\hline No & 1.00 & & 1.00 & \\
\hline Yes & $1.00(0.8 I-I .12)$ & $0.0(0.0-0.06)$ & $1.24(1.03-1.49)$ & $0.08(0.01-0.19)$ \\
\hline \multicolumn{5}{|l|}{ Diabetes } \\
\hline No & 1.00 & & 1.00 & \\
\hline Yes & $1.00(0.62-1.31)$ & $0.0(0.0-0.02)$ & $1.00(0.65-1.4)$ & $0.0(0.0-0.02)$ \\
\hline \multicolumn{5}{|l|}{ Smoking } \\
\hline Never a smoker & 1.00 & & 1.00 & \\
\hline Current smoker & $1.08(0.80-1.45)$ & $0.02(0.0-0.12)$ & $0.65(0.49-1.00)$ & $0.0(0.0-0.0)$ \\
\hline Ex-smoker & $1.46(1.10-1.94)$ & $0.04(0.01-0.07)$ & I.07 (0.44-I.56) & $0.01(0.0-0.04)$ \\
\hline \multicolumn{5}{|l|}{$\mathrm{AMD}^{\S}$} \\
\hline No & 1.00 & & 1.00 & \\
\hline Yes & $0.96(0.58-1.60)$ & - & $1.71(1.01-3.21)$ & - \\
\hline \multicolumn{5}{|l|}{ ARM $\$$} \\
\hline No & 1.00 & & 1.00 & \\
\hline Yes & $1.33(1.04-1.70)$ & - & $1.00(0.72-1.36)$ & - \\
\hline \multicolumn{5}{|l|}{$\begin{array}{l}\text { Nuclear cataract } \\
\text { (LOCS III grade) }\end{array}$} \\
\hline Grade $<2$ & 1.00 & & 1.00 & \\
\hline Grade 2 to 3.5 & 7.61 (6.02-9.32) & $0.76(0.70-0.80)$ & $0.63(0.50-0.78)$ & - \\
\hline Grade $>3.5$ & $7.95(5.37-11.76)$ & $0.23(0.16-0.32)$ & $0.26(0.14-0.49)$ & - \\
\hline
\end{tabular}

Notes: ${ }^{\eta}$ PAR estimates were derived from multivariable logistic regression model and therefore are not additive. The parentheses contain $95 \%$ Cl's; ${ }^{\S}$ MMD and ARM variables were replaced in the multivariable logistic regression model. 
Table 5 Multivariable logistic regression models assessing the adjusted odds ratio $(95 \% \mathrm{Cl})$ of refractive errors

\begin{tabular}{|c|c|c|c|c|}
\hline & $\begin{array}{l}\text { Astigmatism } \\
\text { (Cylinder }<-0.5 \mathrm{D})\end{array}$ & $\mathbf{P A R}^{\eta}$ & $\begin{array}{l}\text { Anisometropia } \\
\text { (SE difference }>0.5 \mathrm{D})\end{array}$ & $\mathbf{P A R}^{\eta}$ \\
\hline \multicolumn{5}{|l|}{ Age (y) } \\
\hline $40-49$ & 1.00 & & 1.00 & \\
\hline $50-59$ & $1.68(1.40-2.02)$ & - & $1.37(1.02-1.84)$ & - \\
\hline $60-69$ & $1.41(1.13-1.75)$ & - & $1.26(1.00-1.74)$ & - \\
\hline$\geq 70$ & $1.37(1.02-1.85)$ & - & $1.52(1.02-2.25)$ & - \\
\hline \multicolumn{5}{|l|}{ Sex } \\
\hline Male & 1.00 & & 1.00 & \\
\hline Female & $1.03(0.84-1.26)$ & - & $1.06(0.79-1.42)$ & - \\
\hline \multicolumn{5}{|l|}{ Socioeconomic status } \\
\hline Extreme lower + lower & $0.94(0.8 \mathrm{I}-1.10)$ & - & - & \\
\hline Middle + upper & 1.00 & & - & \\
\hline \multicolumn{5}{|l|}{ Educational level } \\
\hline Illiterate & 1.00 & & - & \\
\hline Class I-5 & $1.01(0.84-1.21)$ & - & - & \\
\hline Class 6-10 & $1.01(0.79-1.28)$ & - & - & \\
\hline Class II-12 & $1.12(0.73-1.72)$ & - & - & \\
\hline Higher than class 12 & $1.22(0.8 \mathrm{I}-1.82)$ & - & - & \\
\hline \multicolumn{5}{|l|}{ Area } \\
\hline Urban & 1.00 & & - & \\
\hline Rural & $1.38(1.14-1.67)$ & - & - & \\
\hline \multicolumn{5}{|l|}{ Hypertension } \\
\hline No & 1.00 & & - & \\
\hline Yes & $1.19(1.03-1.38)$ & $0.08(0.01-0.16)$ & - & \\
\hline \multicolumn{5}{|l|}{ Diabetes } \\
\hline No & 1.00 & & - & \\
\hline Yes & $1.22(0.88-1.68)$ & $0.01(0.0-0.03)$ & - & \\
\hline \multicolumn{5}{|l|}{ Smoking } \\
\hline Never a smoker & 1.00 & & - & \\
\hline Current smoker & $1.09(0.88-1.34)$ & $0.03(0.0-0.09)$ & - & \\
\hline Ex-smoker & $1.29(0.97-1.72)$ & $0.02(0.0-0.06)$ & - & \\
\hline \multicolumn{5}{|l|}{ AMD $\$$} \\
\hline No & 1.00 & & - & \\
\hline Yes & $2.54(I .54-4.2 I)$ & - & - & \\
\hline \multicolumn{5}{|l|}{ ARM ${ }^{\S}$} \\
\hline No & 1.00 & & - & \\
\hline Yes & $1.08(0.85-1.37)$ & - & - & - \\
\hline \multicolumn{5}{|l|}{$\begin{array}{l}\text { Nuclear cataract } \\
\text { (LOCS III grade) }\end{array}$} \\
\hline Grade $<2$ & - & - & - & \\
\hline Grade 2 to 3.5 & - & - & - & \\
\hline Grade $>3.5$ & - & - & - & \\
\hline
\end{tabular}

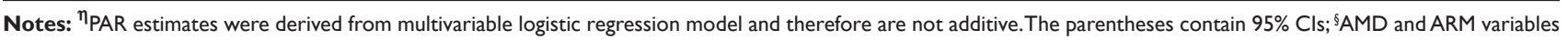
were replaced in the multivariable logistic regression model. 
more myopic, and much of this may have been related to increasing nuclear opacity.

In our population, the prevalence of hyperopia increased with urbanization and educational status and significantly decreased with decreasing socio-economic status (Table 4). We found a significantly higher prevalence of hyperopia in subjects with hypertension, adjusted odds ratio 1.24 (95\% CI: 1.03-1.49; PAR\%: 8\% [95\% CI: 1\%-19\%]). The prevalence of hyperopia significantly decreased with increasing severity of nuclear cataract (Table 4).

There is little population based data available on the prevalence of astigmatism in the elderly. In this report, $31.1 \%$ of the subjects had astigmatism (cylinder $<-0.50 \mathrm{D}$ ). There are difficulties in directly comparing rates of refractive errors reported in different studies, because of differences in participant demographics, definitions of refractive error and inclusion criteria, and research methodology. We found a significant difference $(\mathrm{p}=0.031)$ in rates of refractive error between people with and without diabetes in the univariable analysis, but the statistical significance did not persist in the multivariable analysis. The positive association of other factors such as smoking and hypertension with refractive error contradicts the previously published report. ${ }^{35}$ In our study, we found that ex-smokers had a significantly higher prevalence of myopia, adjusted odds ratio 1.46 (95\% CI: 1.10-1.94; PAR\% 4\% [95\% CI: 1\%-7\%]) compared to never smokers. Smoking contributes to $4 \%$ of avoidable risk of myopia in this population (Table 4). This means that, if we modify this risk factor by appropriate public health intervention, $4 \%$ of the prevalence of myopia attributable to smoking can be eliminated from the population. The odds of prevalence of other refractive errors are higher for ex-smokers but they did not reach statistical significance. We did not try to determine the effects of passive smoking. Presence of hypertension was also significantly associated with higher prevalence of hyperopia and astigmatism (Table 5). This finding too has important implications as hypertension is a modifiable risk factor.

Our study shows that hyperopia was significantly associated with presence of AMD; however, this finding differs from a previously published report in which no association was found between hyperopia and AMD. ${ }^{45}$ We also found a significant association of myopia with ARM (Table 4). The prevalence of astigmatism was also significantly higher in those with AMD, adjusted odds ratio 2.54 (95\% CI: $1.54-4.21$ ) (Table 5). This study did not show a significantly increased association between education and prevalence of myopia (used in support of the use-abuse theory of myopia), unlike several other studies..$^{23-25,28,46,47}$ Indeed, this study actually showed a significantly reduced risk of myopia with lower educational level (up to class 10), which is in accordance with a previously published report. ${ }^{36}$ However, higher educational status was associated with a decreased prevalence of myopia, though this was not statistically significant (Table 4). The mechanism for lower rates of myopia with literacy may not be understood; a possible explanation is that those with no education were more likely to have higher grades of nuclear cataract as compared with those any level of education $(p=0.012)$, and were also more likely to be living in rural areas than in the urban area $(\mathrm{p}<0.0001) .{ }^{48}$ However, the higher prevalence rates of hyperopia among those with higher levels of education found in our study was statistically significant (Table 4).

In conclusion, our study provides further epidemiologic data on the prevalence of refractive errors in an adult Indian population in Asia. This adult population had a much higher prevalence of myopia compared to similarly aged Caucasian populations. The high PAR for nuclear cataract suggests the importance of modifying this risk factor as a public health intervention. The strengths of this study are the representativeness of the sample population, the high response rate, and the standardized protocol. The major limitation of our study is that the data on occupation, were not analysed, and this might be an important potential confounder of the association with refractive error.

\section{Acknowledgments}

The authors thank all the APEDS team, in particular, Lalit and Rakhi Dandona and Catherine McCarty, who designed and conducted the detailed study, all the volunteers who participated in the study, Dr Usha Raman for language editing, and $\mathrm{S}$ Banu for library assistance.

\section{Disclosure}

The authors report no conflicts of interest in this work, which was supported by grants from the Christoffel-Blindenmission, Bensheim, Germany, and the Hyderabad Eye Research Foundation, Hyderabad, India.

\section{References}

1. Dandona R, Dandona L. Refractive error blindness. Bull World Health Organ. 2001;79:237-243.

2. World Health Organization. Programme for the Prevention of Blindness and Deafness. Global Initiative for the Elimination of Avoidable Blindness. Geneva: WHO. 1997. p. 1-7.

3. Dandona L, Dandona R, Naduvilath TJ, et al. Burden of moderate visual impairment in an urban population in Southern India. Ophthalmology. 1999;106:497-504.

4. Dandona L, Dandona R, Naduvilath TJ, et al. Is current eye-care policy focus almost exclusively on cataract adequate to deal with blindness in India? Lancet. 1998;351:1312-1316. 
5. Saw SM, Chua WH, Wu HM, et al. Myopia: gene-environment interaction. Ann Acad Med Singapore. 2000;29:290-297.

6. Saw SM. A synopsis of the prevalence rates and environmental risk factors for myopia. Clin Exp Optom. 2003;86(5):289-294.

7. Guggenheim JA, Hill C, Yam T-F. Myopia, genetics and ambient lighting at night in a UK sample. Br J Ophthalmol. 2003;87:580-582.

8. Dong XD, Ayala M, Lofgren S, et al. Ultraviolet radiation- induced cataract: age and maximum acceptable dosage. Invest Ophthalmol Vis Sci. 2003;44:1150-1154.

9. Saunders KJ. Early refractive development in humans. Surv Ophthalmol. 1995;40:207-216.

10. Tibbenham AD, Peckham CS, Gardiner PA. Vision screening in children tested at 7, 11, and 16 years. Br Med J. 1978;1:1312-1314.

11. Saunders H. An longitudinal study of the age-dependence of human ocular refraction-I. Age-dependent changes in the equivalent sphere. Ophthalmic Physiol Opt. 1986;6:39-46.

12. Northridge ME. Annotation: public health methods: attributable risk as a link between causality and public health action. Am J Publ Health. 1995;85:1202-1204.

13. Rockhill B, Newman B, Weinberg C. Use and misuse of population attributable fractions. Am J Publ Health. 1998;88:15-19.

14. Dandona L, Dandona R, Srinivas M, et al. Blindness in the Indian State of Andhra Pradesh. Invest Ophthalmol Vis Sci. 2001;42:908-916.

15. Dandona R, Dandona L, Naduvilath TJ, et al. Design of a population study of visually impairment in India: the Andhra Pradesh Eye Disease Study. Indian J Ophthalmol. 1997;45:251-257.

16. Dandona R, Dandona L, Naduvilath TJ, et al. Refractive errors in an urban population in Southern India: The Andhra Pradesh Eye Disease Study. Invest Ophthalmol Vis Sci. 1999;40:2810-2818.

17. Chylack LT, Wolfe JK, Singer DM, et al. The lens opacities classification system III. Arch Ophthalmol. 1993;111:831-836.

18. Taylor HR, West SK. A simple system for the clinical grading of lens opacities. Lens Res. 1988;5:175-181.

19. Bird AC, Bressler NM, Bressler SB, et al. An international classification and grading system for age-related maculopathy and age related macular degeneration. The International ARM Epidemiological Study Group. Surv Ophthalmol. 1995;39:367-374.

20. Rosner B. Fundamentals of Biostatistics. 2nd ed. Boston: PWS Publishers; 1986. p. 84-92, 404-408.

21. Pearce N. Analytical implications of epidemiological concepts of interaction. Int J Epidemiol. 1989;18:976-980.

22. Wong TY, Foster PJ, Hee J, et al. Prevalence and risk factors for refractive errors in adult Chinese in Singapore. Invest Ophthalmol Vis Sci. 2000;41:2486-2494.

23. Katz J, Tielsch JM, Sommer A. Prevalence and risk factors for refractive errors in an adult inner city population. Invest Ophthalmol Vis Sci. 1997;38:334-340.

24. Wang Q, Klein BE, Klein R, et al. Refractive status in the Beaver Dam Eye Study. Invest Ophthalmol Vis Sci. 1994;35:4344-4347.

25. Wensor M, McCarty CA, Taylor HR. Prevalence and risk factors of myopia in Victoria, Australia. Arch Ophthalmol. 1999;117:658-663.

26. Attebo K, Ivers RQ, Mitchell P. Refractive errors in an older population: the Blue Mountains Eye Study. Ophthalmology. 1999;106:1066-1072.

27. Wu SY, Nemesure B, Leske MC. Refractive errors in a black adult population: the Barbados Eye Study. Invest Ophthalmol Vis Sci. 1999;40:2179-2184.
28. Saw SM, Katz J, Schein OD, et al. Epidemiology of myopia. Epidemiol Rev. 1996;18:175-187.

29. Lin LLK, Chen CJ, Hung PT. Nation-wide survey of myopia among school children in Taiwan, 1986. Acta Ophthalmol. 1988;66(Suppl):29-33.

30. Lin LL, Shih YF, Tsai CB, et al. Epidemiologic study of ocular refraction among school children in Taiwan in 1995. Optom Vis Sci. 1999;76:275-281

31. Hosaka A. Population studies-myopia experience in Japan. Acta Ophthalmol. 1988;185(Suppl):37-40.

32. Van Newkirk MR. The Hong Kong vision study: a pilot assessment of visual impairment in adults. Trans Am Ophthalmol Soc. 1997;95:715-749.

33. Chew SJ, Chia SC, Lee LKH. The pattern of myopia in young Singaporean men. Singapore Med J. 1988;29:201-211.

34. Chow YC, Dhillon B, Chew PTK, Chew SJ. Refractive errors in Singapore medical students. Singapore Med J. 1990;31:472-473.

35. Cheng CY, Hsu WM, Liu JH, et al. Refractive errors in an elderly Chinese population in Taiwan: The Shihpai Eye Study. Invest Ophthalmol Vis Sci. 2003;44:4630-4638.

36. Bourne RRA, Dineen BP, Ali SM, et al. Prevalence of refractive error in Bangladesh Adults: Results of the national blindness and low vision survey of Bangladesh. Ophthalmology. 2004;111:1150-1160.

37. Saw S, Gazzard G, Koh D, et al. Prevalence rates of refractive errors in Sumatra, Indonesia. Invest Ophthalmol Vis Sci. 2002;43:3174-3180.

38. Raju P, Ramesh V, Arvind H, et al. Prevalence of refractive errors in a rural south Indian population. Invest Ophthalmol Vis Sci. 2004;45:4268-4272.

39. Slataper FJ. Age norms of refraction and vision. Arch Ophthalmol. 1950;43:466-481.

40. Hemenger RP, Garner LF, Ooi CS. Change with age of the refractive index gradient of the human ocular lens. Invest Ophthalmol Vis Sci. 1995;36:703-707.

41. Wong TY, Foster PJ, Ng TP, et al. Variation in ocular biometry in an adult Chinese population in Singapore: the Tanjong Pagar Survery. Invest Ophthalmol Vis Sci. 2001;42:73-80.

42. Bengtsson B, Grodum K. Refractive changes in the elderly. Acta Ophthalmol Scand. 1999;77:37-39.

43. Lim R, Mitchell P, Cumming RG. Refractive associations with cataract: the Blue Mountains Eye Study. Invest Ophthalmol Vis Sci. 1999;40:3021-3026.

44. Lee KE, Klein BE, Klein R, et al. Changes in refraction over 10 years in an adult population: the Beaver Dam Eye Study. Invest Ophthalmol Vis Sci. 2002;43:2566-2271.

45. Wang JJ, Mitchell P, Smith W. Refractive error and age-related maculopathy: The Blue Mountains Eye Study. Invest Ophthalmol Vis Sci. 1998;39:2167-2171.

46. Teasdale TW, Fuchs J, Goldschmidt E. Degree of myopia in relation to intelligence and educational level. Lancet. 1998;10:1351-1354.

47. Wu HM, Seet B, Yap EP, et al. Does education explain ethnic differences in myopia prevalence? A population based study of young adult males in Singapore. Optom Vis Sci. 2001;78:234-239.

48. Dandona R, Dandona L, Srinivas M, et al. Population-based assessment of refractive error in India: the Andhra Pradesh eye disease study. Clin Experiment Ophthalmol. 2002;30:84-93. 
